\title{
As limitações do direito ao esquecimento diante de informações de interesse público
}

\author{
Limitations on the right to be forgotten before information of public interest \\ Limitaciones al derecho al olvidado antes de información de interés público
}

Recebido: 05/01/2022 | Revisado: 10/01/2022 | Aceito: 12/01/2022 | Publicado: 14/01/2022

\author{
Miriam Fecchio Chueiri \\ ORCID: https://orcid.org/0000-0002-8111-4549 \\ Universidade Paranaense, Brasil \\ E-mail: profmiriamfecchio@gmail.com \\ Mariceles Cristhina Fecchio \\ ORCID: https://orcid.org/0000-0002-2129-156X \\ Universidade Paranaense, Brasil \\ E-mail: mfecchio@prof.unipar.br \\ Eduardo Fecchio Botter \\ ORCID: https://orcid.org/0000-0003-3935-4482 \\ Universidade Paranaense, Brasil \\ E-mail: danicne@gmail.com
}

\begin{abstract}
Resumo
Esta pesquisa pretende analisar as limitações do direito ao esquecimento, como ferramenta para coibir ou, até mesmo, dificultar o acesso do cidadão à informações de interesse público. Dessa forma abordando o direito da personalidade, o direito à informação, o direito ao esquecimento, no âmbito civil e processual. O texto discorre sobre situações passadas e atuais acerca da divulgação de fatos ou dados verídicos em que se pretendeu obstar em razão da passagem do tempo, fazendo com que dessa forma tentasse apagar parte da história da nação. Por meio de uma metodologia dedutiva, mediante uma análise doutrinária, legislativa e jurisprudencial, o texto apresenta brevemente o que se estabelece para o exercício do direito ao esquecimento e quais suas limitações. Com o objetivo de promover a defesa da informação como pilar de uma nação, vez que é por meio dela que a história se perfaz, baseada no papel da Constituição em publicizar atos de agentes púbicos no exercício de suas funções. A pesquisa faz parte do projeto "Os princípios constitucionais e o direito digital: os efeitos no âmbito processual civil", que versa sobre as mudanças sociais que os meios digitais e de comunicação geraram e sua valoração no meio jurídico material e processual.
\end{abstract}

Palavras-chave: Direito ao esquecimento; Liberdade de expressão; Direito à informação.

\begin{abstract}
This research intends to analyze the limitations of the right to be forgotten, as a tool to restrain or even hinder the citizen's access to information of public interest. Thus, addressing the right to personality, the right to information, the right to be forgotten, in the civil and procedural sphere. The text discusses past and current situations about the disclosure of facts or truthful data that it was intended to prevent due to the passage of time, thus trying to erase part of the nation's history. Through a deductive methodology, through a doctrinal, legislative and jurisprudential analysis, the text informs the position that Brazilian society establishes for the exercise of the right to be forgotten and what are its limitations. With the objective of promoting the defense of information as a pillar of a nation, since it is through it that history is made, based on the role of the Constitution in publicizing the acts of public agents in the exercise of their functions. The research is part of the project "Constitutional principles and digital law: effects in the civil procedural sphere", which deals with the social changes that digital and communication media have generated and their valuation in the material and procedural legal environment.
\end{abstract}

Keywords: Right to be forgotten; Freedom of expression; Right to information.

\section{Resumen}

Esta investigación pretende analizar las limitaciones del derecho al olvido, como herramienta para frenar o incluso dificultar el acceso del ciudadano a información de interés público. Así, abordando el derecho a la personalidad, el derecho a la información, el derecho al olvido, en el ámbito civil y procesal. El texto discute situaciones pasadas y actuales sobre la divulgación de hechos o datos veraces que se pretendía prevenir por el paso del tiempo, intentando así borrar parte de la historia de la nación. A través de una metodología deductiva, a través de un análisis doctrinal, legislativo y jurisprudencial, el texto informa la posición que establece la sociedad brasileña para el ejercicio del derecho al olvido y cuáles son sus limitaciones. Con el objetivo de promover la defensa de la información como pilar de una nación, ya que es a través de ella que se hace historia, a partir del papel de la Constitución en la difusión de los actos de los agentes públicos en el ejercicio de sus funciones. La investigación se enmarca dentro del proyecto 
"Principios constitucionales y derecho digital: efectos en el ámbito procesal civil", que aborda los cambios sociales que han generado los medios digitales y de comunicación y su valoración en el ámbito jurídico material y procesal.

Palabras clave: Derecho al olvido; La libertad de expresión; Derecho de información.

\section{Introdução}

Desde a antiguidade, a informação sempre esteve presente na vida do ser humano, até mesmo quando ele não tinha noções básicas acerca do que era ou não uma informação. Artes rupestres serviam tanto para contar histórias, como para marcar territórios, e dessa forma informar um transeunte que ali já havia alguém e que talvez não fosse um bom lugar para ele tentar estabelecer moradia.

Até nos dias de hoje, figuras podem ser sinais de informações, ajudando a entender a mensagem que está sendo passada para quem não entende o idioma local. Por exemplo, se estivermos em uma sala com três portas onde na primeira há uma bandeira com uma foice e um martelo entrelaçados, uma bandeira com uma suástica e uma bandeira de gadsden, sabemos que há ali três formas diferentes de pensamento, sem que nenhuma palavra seja escrita, apenas com a informação visual e toda carga histórica que ela carrega.

O Brasil por possuir uma constituição ainda nova, mesmo que próxima de fazer trinta e três anos, foi em um ambiente histórico onde a informação a população era limitada em comparação à atualidade.

Com o avanço da tecnologia, redes descentralizadas, e mais acessíveis, está sendo possível cada vez mais toda população ter acesso a todo tipo de informação, inclusive notícias pagas por paywall de jornais podem ser lidas através de extensões que certos navegadores possuem. Dessa maneira, não há mais o que se falar sobre o cidadão não ter acesso a determinada informação. Com isso, empregados do serviço público, buscam o judiciário com litígios e muitas demandas, exigindo que se faça valer o direito do esquecimento, para que atos que praticaram não mais estejam disponíveis. O que vai na contra-mão de toda questão da publicidade de informações que a Constituição Federal prescreve, acerca de atividades com fim público.

A despeito do direito à privacidade também compor o rol taxativo das diretrizes constitucionais, o direito à informação sobre os atos das pessoas que realizam o serviço público no exercício de suas funções tem total relevância, pois afetas ao interesse público.

\section{Metodologia}

A metodologia utilizada parte da análise descritiva de premissas verdadeiras, as garantias expressas na Constituição Federal - direito à privacidade, como extensão do direito de personalidade (tutelado pelo Código Civil, pela Lei de Proteção de $\operatorname{Dados}^{1}$ e pelo Marco Civil da Internet ${ }^{2}$ ), e direito à informação, bem como, a teoria do direito ao esquecimento. Como afirma Marconi e Lakatos (2003, p. 92) o método dedutivo "tem o propósito de explicar o conteúdo das premissas", com o intuito, no presente trabalho, de sustentar de modo completo a conclusão.

Conforme Galuppo (2008, p.112), "É preciso dizer o que vai ser feito, como vai ser feito, quando, onde e por quê".

Nesse sentido, parte-se da análise da previsão legislativa em relação ao direito de personalidade, que além da proteção expressa no Código Civil, em razão da disseminação de informações no sistema global de redes de computadores interligados (internet), passou a ter previsão de proteção expressa na Lei n ${ }^{\circ}$ 12.965/2014 e Lei n ${ }^{\circ}$ 13.709/2018, como forma de limitação no uso e publicidade de informações. A parte introdutória é importante para tratar, no que se seguirá, na análise do direito à

\footnotetext{
${ }^{1}$ Lei no ${ }^{\circ} \quad 13.709 / 2018$
}

${ }^{2}$ Lei $\mathrm{n}^{\circ} 12.965 / 2014$ 
informação, do direito à privacidade e a teoria do direito ao esquecimento. Estudo que se complementa com utilização de alguns exemplos de jurisprudências para compor a base argumentativa.

\section{Discussões e Resultados}

\subsection{Direitos da personalidade}

Precipuamente, como direito ao esquecimento, como se verá compõe base argumentativa abarcada pois trata diretamente dos direitos da personalidade, assim se faz necessário fazer pontuações sobre alguns aspectos dos direitos da personalidade.

A Constituição Federal de 1.988 foi essencial para firmar o Estado Democrático de Direito no Brasil, pois apresentou diversas novidades ao mundo jurídico do país, e, ainda, resgatou alguns dos direitos que foram abandonados e ignorados durante o período da ditadura militar. Trouxe entre suas inovações o acolhimento de princípios presentes na Declaração de Direitos Humanos, destacando direitos como a liberdade de expressão, informação, pensamento e entre outros.

É importante mencionar que o princípio da dignidade humana é um dos principais pilares do ordenamento jurídico brasileiro, e que se transformou em um suporte para a aceitação e evolução dos direitos da personalidade.

De acordo com Carlos Roberto Gonçalves (2012, p. 135) os direitos da personalidade estão fundamentados no fato de que existem outros direitos que vão além daqueles que são economicamente aferíveis e que não possuem ligação direta com o ser humano, tais direitos estão intimamente ligados com a pessoa humana, estes são inseparáveis e estão ligados ao ser humano de maneira infindável, como por exemplo: a imagem, o nome, a liberdade e o direito à vida.

A Constituição Federal, incluiu a proteção aos direitos da pessoa entre os direitos fundamentais, em seu artigo $5^{\circ}$, inciso X, que determina: "são invioláveis a intimidade, a vida privada, a honra e a imagem das pessoas, assegurado o direito a indenização pelo dano material ou moral decorrente de sua violação". Tal inclusão foi de suma importância para a garantia e tutela dos mencionados direitos no Brasil, que até então estavam sendo tutelados apenas por leis especiais e pela jurisprudência.

Ainda, o Código Civil de 2002, reservou o capítulo II para tratar dos Direitos da Personalidade, onde segundo Carlos Alberto Bittar " $[\ldots]$ o legislador versou sobre as principais categorias dos direitos da personalidade, a saber, sobre os direitos físicos (corpo, cadáver, partes do corpo), psíquicos (intimidade, vida privada) e morais (nome, honra) [...]”. (2015, p. 21)

O Código Civil, aponta as características dos direitos da personalidade em seu artigo 11, expressando que são intransmissíveis e irrenunciáveis, ou seja, são indisponíveis, assim seus titulares não podem transmitir seus direitos para outra pessoa, pois tais direitos são inseparáveis de seus titulares. Mas há exceções, como o direito à imagem, que pode ser cedido, em situações em que há a utilização da imagem de forma comercial, mediante pagamento. Dessa forma, é possível concluir que a indisponibilidade dos direitos da personalidade não é uma característica absoluta, podendo haver situações determinadas em que tais direitos poderão ser disponíveis. Ainda, são imprescritíveis, impenhoráveis, não são sujeitos a desapropriação, e entre outras características.

Outrossim, se faz necessário mencionar que os Direitos da Personalidade também são tutelados pela Lei 12.965/2014 em seu artigo 10, que determina que os provedores de conexão e aplicação da internet deverão resguardar intimidade, a vida privada, a honra e a imagem das partes. Além disso, também é mencionado no artigo 23, onde preceitua que o julgador deverá observar as diligências que sejam capazes de garantir a proteção dos mencionados direitos.

Mais recentemente, passou a viger a Lei 13.709/2018, conhecida como Lei de Proteção de Dados Pessoais, que possui como finalidade proteger os direitos da personalidade dos cidadãos, como a privacidade e os dados pessoais. Assim, ao analisar a referida Lei, já se observa desde o início o objetivo de proteger a personalidade dos usuários, o artigo $2^{\circ}$ preceitua: 
A disciplina da proteção de dados pessoais tem como fundamentos: I - o respeito à privacidade; II - a autodeterminação informativa; III - a liberdade de expressão, de informação, de comunicação e de opinião; IV - à inviolabilidade da intimidade, da honra e da imagem; V - o desenvolvimento econômico e tecnológico e a inovação; VI - a livre iniciativa, a livre concorrência e a defesa do consumidor; VII - os direitos humanos, o livre desenvolvimento da personalidade, a dignidade e o exercício da cidadania pelas pessoas naturais.

Legislações recentes que servem como meio atual de regulamentação de proteção de direitos em razão da disseminação de informações no sistema global de redes de computadores interligados (internet).

\subsection{Direito à informação}

Mendel, cita que a noção de liberdade de informação foi reconhecida pela ONU em 1946, bem diferente da democracia que teve como sua primeira experiência em mais de 500 anos antes de Cristo, a disseminação da informação como regra aconteceu só através da Declaração Universal de Direitos Humanos (DUDH), adotada pela ONU em 10 de dezembro de 1948 e, posteriormente, o Pacto Internacional de Direitos Civis e Políticos (ICCPR - ratificado no Brasil pelo Decreto ${ }^{\circ}$. 592 , de 06 de julho de 1992), adotado pela ONU em 1966 e ratificado por 160 Estados em julho de 2007, são apontados como os primeiros instrumentos legais internacionais a garantir a liberdade de expressão e opinião, incluindo-se aí a liberdade de buscar e receber informações. (Mendel, 2009, p. 8; Gruman, 2012, p. 99).

Observa-se no artigo 19 da Declaração Universal dos Direitos Humanos o seguinte texto: “Todo ser humano tem direito à liberdade de opinião e expressão; este direito inclui a liberdade de, sem interferência, ter opiniões e de procurar, receber e transmitir informações e ideias por quaisquer meios e independentemente de fronteiras". Desse modo, não há o que se falar em violação aos Direitos Humanos no acesso à informação, muito menos ainda ao analisar de um prisma no qual o interesse público é o maior beneficiado, vez que é obrigado a ser parte do processo democrático por meio do implícito Contrato Social, sendo assim também o maior interessado para que fatos acontecidos não sejam esquecidos da história.

Parte dos historiadores afirmam que a informação a qual a DUDH se refere é acerca de informações relacionadas às violações de direitos humanos e o resgate da memória histórica de um país. No Brasil a Constituição já assegura o direito à informação pública no artigo $5^{\circ}$, inciso XXXIII que nos expressa: "todos têm direito a receber dos órgãos públicos informações de seu interesse particular, ou de interesse coletivo ou geral, que serão prestadas no prazo da lei, sob pena de responsabilidade, ressalvadas aquelas cujo sigilo seja imprescindível à segurança da sociedade e do Estado”.

Nesse momento há diversos litígios alegando direito ao esquecimento, para que atos passados não venham à tona. No entanto, no que diz respeito à informação, um dado de interesse público não carrega juízo de valor, sendo dessa maneira algo que deve ser de livre e constante acesso a qualquer cidadão que os queira.

É entendimento pacífico no STF que o Direito ao Esquecimento não é compatível com a Constituição Federal. Sendo dessa forma impossível impedir divulgação de dados ou fatos verídicos passados como regra, tendo que analisar caso a caso, uma vez que tal divulgação pode sim responder civilmente e penalmente caso tenha infringido alguma lei previamente estabelecida, o que no caso, não considera a plena divulgação uma delas.

Muito se fala em direito à obscuridade para proteção ao direito em determinadas situações, uma vez que como afirma Uncular (2019, p. 311) é impossível que os dados sejam completamente esquecidos simplesmente pela remoção das listas de um motor de busca.

Um ex-participante de um programa de reality show da televisão entrou com um pedido contra o Google (processo $\mathrm{N}^{\text {o: }}$ 1006549-02.2020.8.26.0004), para que removesse determinadas matérias acerca de suas ações no programa, o que foi rejeitado pela $7^{\text {a }}$ Turma Cível do Colégio Recursal de São Paulo, vez que as reportagens a qual a parte autora requeria a retirada era apenas as que constavam com comentários que por ele eram reprováveis, não mencionando as que faziam elogios para ele. Dessa forma, notava-se que queria não ser esquecido, e sim apenas que as informações sobre atitudes não compatíveis 
com sua própria decisão fossem retiradas. Por questão dos fatos serem verídicos e não haver nenhuma ilicitude no ato de propagar notícias, a juíza além de indeferir o pedido, fez-se também menção ao entendimento do STF sobre o famigerado caso de Aída Curi.

\section{O Valor da Privacidade}

Em tempos mais antigos, a privacidade era menos violada no sentido de perdurar a informação ao longo do tempo, o que atualmente com o crescimento do grupo Google, Meta e demais empresas de tecnologias que usam todas suas informações inseridas na internet para descobrir o seu padrão e explorar isso tanto socialmente como financeiramente, acaba estimulando as pessoas para que alimentem o algoritmo com o maior número de textos, fotos e vídeos que irão perdurar para sempre.

A busca da privacidade além da ocultação de determinados atos, também se fala sobre a total remoção para que aquilo não possa ser acessado novamente. O que está gerando um certo debate, uma vez que informações inseridas em redes que seguem uma blockchain, por exemplo, não haveria a possibilidade de exclusão daquele conteúdo.

Essa preocupação já era transmitida por Viktor Mayer-Schönberger em 2009, ele que foi um dos precursores acerca do Direito ao Esquecimento, afirmava que o ato de deletar as informações disponíveis na internet, não seria garantia de que haveria definitiva exclusão.

A sua privacidade resguarda para si os seus desejos e preferências subjetivas sobre todo e qualquer assunto, onde qualquer empresa que tiver o interesse em se comunicar com você, ao acessar os seus dados privados sem a sua permissão, teria um poder muito forte de influência. Por isso o grande debate sobre o que os sites, as redes sociais, os aplicativos de mensagens, etc., podem fazer com toda informação que você disponibiliza.

As redes de web 3.0 estão tentando resolver essa questão da privacidade e o valor que o usuário deveria receber pelas suas informações, partindo da ideia de Mayer-Schönberger de que as informações, nunca serão de fato apagadas. Dessa maneira, ao menos o usuário que está fornecendo seus dados terá um retorno financeiro, e as empresas que quiserem conhecer o seu usuário terão que pagar por isso.

Esse valor ainda é um tanto subjetivo, como pode ser notado por exemplo, em anúncios do Instagram, onde cada quantidade de usuários que a empresa gostaria de atingir terá um custo diferenciado, dependendo do quão nichado o produto se encontra.

\section{Direito ao Esquecimento}

O direito ao esquecimento ergueu-se diante de uma perspectiva voltada à integridade moral dos indivíduos e, principalmente, à preservação da vida privada. Tal direito está fundamentado no princípio da dignidade humana. Possui como finalidade a proteção de direitos personalíssimos, restringindo as ações externas, evitando e até mesmo remediando lesões aos direitos da personalidade.

O direito ao esquecimento, garante aos cidadãos, mediante determinados aspectos, a alternativa de terem algumas de suas informações (passadas) esquecidas. Ou seja, possibilita ao indivíduo a oportunidade de impedir que certas informações a seu respeito sejam expostas por tempo ilimitado.

No atual contexto da sociedade, em que a tecnologia e a internet estão se desenvolvendo de maneira acelerada, o direito ao esquecimento tomou destaque, haja vista que as informações expostas na internet podem ser acessadas a qualquer momento e em qualquer lugar, ou seja, não há barreiras temporais e geográficas, o que pode resultar em lesão aos direitos da personalidade.

Atualmente a internet é uma grande detentora de diversos dados pessoais, de milhares de pessoas, e o uso e destinação inapropriada por parte dos fornecedores de internet e aplicações podem gerar grandes prejuízos aos seus usuários. 
Diante deste cenário, surgiu a Lei 13.709/18, a denominada Lei Geral de Proteção de Dados, que possui como objetivo tutelar e resguardar a liberdade e a privacidade dos usuários, sejam eles pessoas físicas ou jurídicas de direito público ou privado. Entretanto, a referida lei não faz referência expressa ao direito ao esquecimento, mas é uma grande aliada daqueles que o defendem, pois, a LGPD apresenta diversas determinações de como os dados pessoais devem ser tratados pelos agentes. Uma destas determinações se encontra no artigo 46, o qual determina que: "Art. 46. Os agentes de tratamento devem adotar medidas de segurança, técnicas e administrativas aptas a proteger os dados pessoais de acessos não autorizados e de situações acidentais ou ilícitas de destruição, perda, alteração, comunicação ou qualquer forma de tratamento inadequado ou ilícito”. E, ainda, estipula sanções administrativas aos agentes de tratamento de dados que infringirem as determinações.

Por se viver em uma sociedade, onde deve-se por primazia seguir o Contrato Social, é necessário tratar de uma função social da informação. Não se pode permitir que pessoas não tenham acesso a fatos passados por ação de indivíduos querendo apagar a história e assim esconder da sociedade acontecimentos que possam vir a ser de seu interesse.

Alguns doutrinadores referem-se ao tema de forma objetivamente distinta em relação a terminologia, utilizando-se de direito ao esquecimento, relacionado a privacidade e intimidade do indivíduo, e o direito fundamental à memória, relacionado ao patrimônio cultural de um povo. Como afirma Maurmo (2017): "O direito ao esquecimento não se opõe ao direito fundamental à memória, pelo simples fato de que seus objetos não coincidem: enquanto este repousa sobre o patrimônio histórico e cultural de um povo, aquele envolve dados particulares". Todavia, há entes que voluntariamente ou involuntariamente são pessoas públicas que realizam atos no exercício da sua função, a divulgação desses atos caracteriza interesse público.

De acordo com o Enunciado 531 da VI Jornada de Direito Civil do Conselho Federal de Justiça, a interpretação que se deve dar ao direito ao esquecimento, trata-se: "A tutela da pessoa humana na sociedade da informação inclui o direito ao esquecimento". Assim, no contexto cultural em que foi criada a Constituição Federal de 1988, a liberdade de expressão, e portanto de informação, está sedimentada nos incs. IV e IX do art. $5^{\circ}$, como premissa de barrar a censura. Contudo, a doutrina que defende o direito ao esquecimento, baseia-se no exercício amplo da dignidade do ser humano, que poderá ser abalado quando violada sua intimidade ou privacidade.

Não há como abordar temas complexos como o Direito ao Esquecimento, sem citar o Recurso Extraordinário número 1010606, caso Aída Curi, mencionado anteriormente. Quando uma pessoa se torna parte de algo que a transforma em um ente de interesse público, o direito à informação se faz necessário para que o acesso ao conteúdo gerado com ou sem intenção chegue até o cidadão comum. Neste sentido, a R.E. em sua tese define:

É incompatível com a Constituição a ideia de um direito ao esquecimento, assim entendido como o poder de obstar, em razão da passagem do tempo, a divulgação de fatos ou dados verídicos e licitamente obtidos e publicados em meios de comunicação social analógicos ou digitais. Eventuais excessos ou abusos no exercício da liberdade de expressão e de informação devem ser analisados caso a caso, a partir dos parâmetros constitucionais - especialmente os relativos à proteção da honra, da imagem, da privacidade e da personalidade em geral - e das expressas e específicas previsões legais nos âmbitos penal e cível (Recurso Extraordinário 1.010.606, Rio de Janeiro. Supremo Tribunal Federal ${ }^{3}$ ).

No referido acórdão, após apreciar o Tema $\mathrm{n}^{\circ} 786^{4}$ de Repercussão Geral, os ministros do STF defenderam a divulgação de informações, mantendo a liberdade de expressão da imprensa, ao mesmo tempo que defende a vida privada do

\footnotetext{
${ }^{3}$ Acórdão na íntegra: https://portal.stf.jus.br/processos/downloadPeca.asp?id=15346473757\&ext=.pdf

${ }^{4} 786$ - "É incompatível com a Constituição Federal a ideia de um direito ao esquecimento, assim entendido como o poder de obstar, em razão da passagem do tempo, a divulgação de fatos ou dados verídicos e licitamente obtidos e publicados em meios de comunicação social - analógicos ou digitais. Eventuais excessos ou abusos no exercício da liberdade de expressão e de informação devem ser analisados caso a caso, a partir dos parâmetros constitucionais, especialmente os relativos à proteção da honra, da imagem, da privacidade e da personalidade em geral, e as expressas e específicas previsões legais nos âmbitos penal e cível".
} 
cidadão trazendo a proteção para excessos e abusos serem tratados nas esferas cível e penal. Assim sendo, não há o que falar em manutenção de falsas mensagens, vez que a proteção à informação se trata de fatos verídicos e licitamente obtidos, também não deixando lacunas para que a sociedade não se sinta vulnerável quando alguém compartilhar tal informação de forma desproporcional.

Até em casos mais graves como o caso do goleiro Bruno, não caberia o argumento de direito ao esquecimento para que não venha à tona a situação lamentavelmente ocorrida. Inclusive já foi matéria no STF através do Recurso Extraordinário 593818 de Santa Catarina ${ }^{5}$, em que trata sobre assento do Tribunal de não ser possível considerar, para a fixação da pena-base, condenações criminais extintas à mais de cinco anos, por não poderem ser tidas como maus antecedentes. No referido julgado, foi utilizada como argumento a seguinte citação:

É dito frequentemente que a teoria da aplicação da pena é um ramo cientificamente subdesenvolvido no âmbito das ciências penais, e que não raro elementos irracionais, preconceitos arraigados, são os verdadeiros fatores que conduzem o juiz na tarefa de determinação da pena concreta. (Teixeira, 2015. p. 21).

Porém o Relator Min. Roberto Barroso afirmou que:

Não se pode retirar do julgador a possibilidade de aferir, no caso concreto, informações sobre a vida pregressa do agente para fins de fixação da pena-base em observância aos princípios constitucionais da isonomia e da individualização da pena.

Assim, observou-se que o prazo quinquenal depurador não se aplica aos maus antecedentes, de modo que não há limitação temporal.

Outro cidadão que não tem o direito ao esquecimento acerca de atos relacionados a sua vida é o servidor público, onde o TRF da $4^{\text {a }}$ Região em 2009, entendeu que tanto eles, quanto os exercentes ou candidatos à vida pública possuem uma vida pretérita que interessa a população ${ }^{6}$. Tendo julgado um caso onde um servidores federal pleiteou na justiça a exclusão de seus registros relacionado a demissão e admissão anteriores, como consta na Apelação Cível: AC 58151 PR 2003.70.00.058151-6:

RESPONSABILIDADE CIVIL. DANOS MORAIS. SERVIDOR PÚBLICO. DIREITO AO ESQUECIMENTO. ARTIGO 5', INCISO X, DA CONSTITUIÇÃO FEDERAL. 1. A divulgação das informações relativas à anterior demissão e readmissão do autor, para que se configurasse ilícita, era necessário que ele tivesse obtido, por qualquer meio, a decretação do sigilo dessas informações, o que não ocorreu. A divulgação das informações referidas, que expressaram a verdade dos fatos que se extrai do processo judicial pertinente, não pode ser tida como ilícita, já que não se subsume o caso a qualquer das hipóteses legais de sigilo ordinário. 2. Embora se possa cogitar em tese sobre um direito ao esquecimento, impeditivo de que longínquas máculas do passado possam ser resolvidas e trazidas a público, tal segredo da vida pregressa relaciona-se aos aspectos da vida íntima das pessoas, não podendo ser estendido ao servidor público, ou pessoas exercentes ou candidatos à vida pública, pois mais do que meros particulares, devem explicações ao público sobre a sua vida funcional pretérita ou presente. Note-se que a matriz constitucional de onde se pode extrair o direito ao esquecimento radica no artigo $5^{\circ}$, inciso $\mathrm{X}$, e inicia dizendo que são invioláveis a intimidade, a vida privada, etc., claramente afastando situação de vida funcional. (TRF-4 - AC: 58151 PR 2003.70.00.058151-6, Relator: MARGA INGE BARTH TESSLER, Data de Julgamento: 06/05/2009, QUARTA TURMA).

\footnotetext{
${ }^{5}$ Acórdão na íntegra: https://redir.stf.jus.br/paginadorpub/paginador.jsp?docTP=TP\&docID=754448246

${ }^{6}$ Em tentativa discutível, foi apresentada à Câmara de Debutados o Projeto de Lei no $10087 / 2018$ que: propõe que a liberdade de expressão prevaleça sobre o direito ao esquecimento caso envolva pessoa pública". https://www.migalhas.com.br/depeso/281073/o-direito-ao-esquecimento-e-a-pessoa-publica
} 
Situações semelhantes destacaram-se em outros julgados, como na Apelação Cível no 0716588-42.2018.8.07.0001, julgada pela $3^{\text {a }}$ Turma Cível do Tribunal de Justiça do Distrito Federal, acórdão no $1186782^{7}$ :

EMENTA DIREITO CONSTITUCIONAL. DIREITO CIVIL E PROCESSUAL CIVIL. AUSÊNCIA DE IMPUGNAÇÃO ESPECÍFICA. INOCORRÊNCIA. PRELIMINAR REJEITADA. RECURSO CONHECIDO. INDENIZAÇÃO. DANOS MORAIS. INFORMAÇÕES DISPONIBILIZADAS POR SÍTIO DE BUSCAS MANTIDO NA REDE MUNDIAL DE COMPUTADORES. PRETENSÃO DE EXCLUSÃO DE INFORMAÇÕES. DIREITO AO ESQUECIMENTO. INVIABILIDADE. RECURSO DESPROVIDO. 1. Na presente hipótese, o autor requereu a apreciação de requerimento de exclusão, da rede mundial de computadores, de todas as informações que contenham seu nome ou o nome de seus familiares, concernentes à "Operação Perfídia", deflagrada pela Polícia Federal em conjunto com o Ministério Público Federal, como um dos desdobramentos da "Operação Lava Jato". 2. Constatado que as razões recursais articuladas pelo recorrente guardam relação com os fundamentos da sentença, a preliminar de ausência de impugnação específica não pode ser acolhida. 3. Deve ser evidenciado, no caso, que o exercício da liberdade de imprensa e a livre manifestação do penamento estão em harmonia com o interesse público e estão fundamentados em princípios constitucionais que têm maior peso do que aqueles que resguardam a esfera de intimidade dos indivíduos, especialmente em situações atinentes à averiguação de condutas que eventualmente importem na dilapidação do patrimônio público. 4. A retirada, de forma indiscriminada, de dados da plataforma de provedor de pesquisas na rede mundial de computadores importaria na imposição de verdadeira censura, que é expressamente vedada pelo art. $5^{\circ}$, inc. IX, do Texto Constitucional. 5. Por se tratar de buscador virtual, sem o controle dos dados disponibilizados pelos fornecedores de conteúdo de suas plataformas de pesquisa, o sítio eletrônico Google não pode ser responsabilizado pela divulgação das informações contestadas ou ser compelido a selecionar notícias não previamente indicadas pela parte. 5.1. Essa tarefa deve ser cumprida pelos próprios interessados, mediante a indicação exata do conteúdo, dos termos e expressões que constituam elos de ligação com sítios eletrônicos que ostentem informações porventura ofensivas ou inverídicas. 6. Com efeito, de acordo com o entendimento firmado pelo Colendo Superior Tribunal de Justiça "os provedores de pesquisa virtual não podem ser obrigados a eliminar do seu sistema os resultados da busca de determinado termo ou expressão, tampouco os resultados que apontem para foto ou texto específico, independentemente da indicação do URL da página em que estiverem inseridos." (AgRg no AREsp n ${ }^{\circ}$ 730.119/RJ, Rel. Ministro JOÃO OTÁVIO DE NORONHA, TERCEIRA TURMA, julgado em 02/06/2016, DJe 09/06/2016). 7. A divulgação de informação relevante e contemporânea aos fatos, objeto de apuração em matérias jornalísticas disponibilizadas pelos sítios eletrônicos de busca não se enquadra em situação de "direito ao esquecimento". 8. Preliminar rejeitada. Recurso desprovido.

Observa-se que o respaldo de liberdade de expressão se sobressai quando em conflito com a aplicabilidade de direito ao esquecimento, entretanto, observado no caso concreto ofensa à direito da personalidade que consequentemente cause prejuízo ao exercício da dignidade do indivíduo, poderá ser concedida a retirada ou proibida a divulgação de informações por qualquer meio, aparado em especial pela garantia de preservação do direito à privacidade e intimidade expressos na Constituição (art. $5^{\circ}$, X) e legislação especifica aplicada à internet, LGPD e o Marco Civil da Internet.

\section{Conclusão}

Tendo como base as decisões recentes do Supremo Tribunal Federal, há de se notar que a discussão sobre qual o limite do direito ao esquecimento para que não se sobreponha o direito à informação é um tópico ainda muito recente que trará no decorrer dos anos com o avanço da internet muito mais discussões. As recentes tecnologias vão em direção a cada vez mais disponibilizar informações e evitar que sejam apagadas ao ponto que vão aderindo ao modelo do blockchain, podendo ser difíceis de serem acessadas, porém nunca extintas.

Entende-se que o modo de julgar definido pelo STF de analisar caso a caso no momento seja o mais apropriado, não deixando uma brecha para que possam acusar a última instância de estar fazendo o papel de legislador e definindo uma maneira de ser, mas sim abrindo espaço para um futuro debate na câmara tendo como argumentos cada caso com suas peculiaridades.

\footnotetext{
7 Acórdão na íntegra: https://www.tjdft.jus.br/consultas/gerenciamento-de-precedentes/irdr/0702383-40-2020-8-07-0000-1600450330541-48751-acordao1.pdf
} 
Quanto antes a sociedade através de seus representantes debaterem o tema de maneira não-superficial, conseguir-se-á desenvolver uma regra tipificada para que o judiciário possa seguir como norte, assim diminuindo demandas para a Suprema Corte acerca do citado assunto, e com isso dando mais segurança jurídica para proteger os direitos tanto da informação quanto da vida privada.

\section{Referências}

Apelação Cível n ${ }^{o}$ 2003.70.00.058151-6/PR (2009). $4^{\text {a }}$ Turma do TRF $4^{\text {o }}$ Região. https://www2.trf4.jus.br/trf4/processos/visualizar_documento_ged pro.php?local $=$ trf4\&docum ento $=2920286 \&$ hash $=$ aa 45 b86ce $634077 \mathrm{f} 2 \mathrm{fdb} 098 \mathrm{c} 39501940$

Apelação Cível $\mathrm{n}^{\mathrm{o}}$ 0716588-42.2018.8.07.0001. (2020). $3^{\mathrm{a}}$ Turma Cível do Tribunal de Justiça do Distrito Federal. https://www.tjdft.jus.br/consultas/gerenciamento-de-precedentes/irdr/0702383-40-2020-8-07-0000-1600450330541-48751-acordao-1.pdf

Bittar, C. A. (2015). Os Direitos da Personalidade. (8a ed.), Saraiva.

Borges, L. A. S. (2021). O Direito ao Esquecimento e seus Possíveis Impactos no Estado Democratico de Direito Brasileiro: limites entre as liberdades de expressão e informação e os direitos da personalidade. https://repositorio.pucgoias.edu.br/jspui/handle/123456789/1887.

Código de Processo Civil (2015). Lei 13.105, 16/03/2015. http://www.planalto.gov.br/ccivil_03/_ato2015-2018/2015/lei/113105.htm

D’Almeida, É. N. S. (2020). Disseminação não consensual de imagens íntimas. Uma análise à luz do regulamento geral de proteção de dados. Dissertação (Mestrado em Direito) - Faculdade de Direito da Universidade de Coimbra. Coimbra. p. 101. 2020. https://eg.uc.pt/handle/10316/92692.

Declaração Universal dos Direitos Humanos (1948). Organização das Nações Unidas. https://www.unicef.org/brazil/declaracao-universal-dos-direitoshumanos.

Gonçalves, C. R. (2012). Direito Civil Brasileiro. 1. Parte Geral. (10a ed.), Saraiva.

Gruman, M. (2012, setembro-dezembro). Lei de Acesso à Informação: notas e um breve exemplo. Revista Debates, UFRGS, 6(3), 97- 108. https://seer.ufrgs.br/debates/article/view/34229/23345.

Lei 12.965 de 23 de abril de 2014. (2014). Estabelece princípios, garantias, direitos e deveres para o uso da Internet no Brasil. http://www.planalto.gov.br/ccivil_03/_ato2011-2014/2014/lei/112965.htm

Lei 13.709 de 14 de agosto de 2018. (2018). Lei geral de proteção de dados. http://www.planalto.gov.br/ccivil_03/_ato2015-2018/2018/lei/113709.htm

Maurmo, Júlia Gomes Pereira (2017). Direito ao Esquecimento. https://enciclopediajuridica.pucsp.br/verbete/149/edicao-1/direito-ao-esquecimento.

Mendel, Toby (2009). Liberdade de informação: um estudo de direito comparado. (2a ed.), UNESCO. https://www.gov.br/acessoainformacao/pt-br/centralde-conteudo/publicacoes/arquivos/liberdade-informacao-estudo-direito-comparado-unesco.pdf.

Mayer-Schönberger, Viktor (2009). Delete: the virtue of forgetting in the digital age. New Jersey: Princeton University. https://www.researchgate.net/publication/52010990_Book_review_Viktor_Mayer-Schonberger_Delete_the_virtue_of_forgetting_in_the_digital_age.

Recurso Extraordinário 1010606/RJ (2021). Supremo Tribunal Federal. Relator: Min. Dias Toffoli. Tribunal Pleno. https://jurisprudencia.stf.jus.br/pages/search/sjur446557/false.

Recurso Extraordinário 593818/SC (2020). Supremo Tribunal Federal. Relator: Min. Roberto Barroso. Tribunal Pleno. https://jurisprudencia.stf.jus.br/pages/search/sjur436815/false.

Recurso Inominado n. 1006549-02.2020.8.26.0004/SP (2021, 25 de junho). Tribunal de Justiça de São Paulo Relatora Luciana Novakoski F. A. de Oliveira. https://www.conjur.com.br/dl/gui-napolitano.pdf.

Uncular, S. (2019). The right to removal in the time of post-google Spain: myth or reality under general data protection regulation? International Review of Law Computers \& Technology. 33(3). https://www.tandfonline.com/doi/abs/10.1080/13600869.2018.1533752?journalCode=cirl2\&. 